DOI 10.37882/2500-3682.2020.06.06

\title{
РИТУАЛЬНАЯ ПИЩА В АЛТАЙСКОМ КАЛЕНДАРНОМ ОБРЯДЕ «ЗЕЛЕНАЯ ЛИСТВА» В НАЧАЛЕ ХХІ В.
}

\section{RITUAL FOOD IN THE ALTAI CALENDAR RITE «GREEN FOLIAGE» AT THE BEGINNING OF THE XXI CENTURY \\ E. Enchinov}

Summary: The article discusses the traditions of ritual food in the Altai culture. Altai cuisine was based on dairy, meat and vegetable foods. In the course of historical development during the twentieth century. the consumption of food industry products increased, but in the Altai ceremonies the norm of ritual offerings to spirits was preserved only with traditional products. Ritual food before being delivered to the recipient goes through a number of stages in its preparation, this is the preparation of the basic ingredients, the preparation of food in special ways, the offering in the appropriate ritual action. Through offerings between man and the sacred world, a dialogue is established whose purpose is to ask for well-being and fertility for people, land, animals.

Keywords: altaians, ethnography, traditions, custom, rite, ritual, food.

\author{
Енчинов Эркин Валериевич \\ К.и.н., с.н.с., БНУ РА «Научно-исследовательский \\ институт алтаистики им. С.С. Суразакова», \\ 2. Горно-Алтайск \\ enchinov_e@mail.ru
}

Аннотация: В статье рассматриваются традиции ритуальной пищи в алтайской культуре. Основу алтайской кухни составляли молочная, мясная и растительная пища. В ходе исторического развития в течение XX в. росло потребление продуктов пищевой промышленности, но в обрядах алтайцев сохранилась норма ритуальных подношений духам только традиционными продуктами. Ритуальная пища, прежде чем будет доведена до адресата, проходит ряд этапов в своем приготовлении, это подготовка базовых ингредиенТов, приготовление пищи особыми способами, подношение на соответствующем обрядовом действии. Посредством подношений между человеком и сакральным миром устанавливается диалог целью которого является спрашивание благополучия и плодородия для людей, земли, животных.

Ключевые слова: алтайцы, этнография, традиции, обычай, обряд, ритуал, пища.

К.Э. Укачина, Е.Е. Ямаева, В.А. Муйтуева, М.П. Чочкина, С.П. Тюхтенева, Н.Р. Ойноткинова, Э.В. Енчинов и др.

При этом при описании и анализе собственно календарной обрядности в меньшей мере исследователями уделяется внимание таким традиционным категориям как одежда и пища. В данной работе, на примере весенних молений Зеленая листва, мы бы хотели только обозначить контуры проблематики ритуальной пищи, описать ритуальный пищевой набор, который используется в современной алтайской календарной обрядности.

Коротко скажем о генезисе алтайского народного календаря. Алтайский календарь по системе летоисчисления входит в систему центрально-азиатских календарей, состоящих из 12-летнего животного цикла. Существуют две точки зрения по поводу появления данного типа календаря. Первая, то что предположительно данная система была привнесена на территорию Горного Алтая хуннами во II в. до н.э. - І в. н.э., которые заимствовали в свою очередь у китайцев [3, с. 4]. Вторая, что данный календарь возник именно среди кочевников Центральной Азии, и большое влияние на это оказал их образ жизни. Так, например, по мнению В.В. Цыбульского, «есть основание предполагать, что идея создания юпитерного календаря с небесной символикой 12-летнего животного цикла была воспринята Восточной Азией от кочевников Центральной Азии» [2, с. 79]. 
Обряды и ритуалы календарного цикла помимо того, что могут проводиться на семейно-родовом уровне, они также отправляются коллективно, когда несколько селений или даже целый район проводят совместное моление. Местом совершения обряда, в частности весенних и осенних молений является общеизвестное сакральное место того или иного района. Отправлять культы может не каждый человек, эту роль могут выполнять своего рода «специалисты» по обычаям, в эту категорию входят «знающий» человек - неме билер кижи, шаман - кам или служитель культа белой веры бурханизма - дьарлыкчы, каждый из них может быть ведущим и распорядителем ритуальных действий. Всю необходимую помощь во время совершения обрядов ведущему оказывает группа его помощников шабачы.

Обряды календарного цикла в виду своей массовости, участия разнополых и разновозрастных людей требуют тщательной подготовки. При этом одному человеку и даже одной отдельно взятой семье не по силам провести всю подготовительную часть мероприятия [1, с. 195]. Подготовка к весеннему молению начинается с прихода тепла, что соответствует середине апреля, началу мая.

За время подготовительных мероприятий, ведущий должен успеть определить точное время, место и день совершения обряда, также подготовить материальную базу молений.

В перечень подготовки материальной базы входит, подготовка священных атрибутов, приготовление ритуальной пищи, обустройство священного места для проведения обряда.

Подготовка ритуальной пищи является чуть ли не самой сложной частью всего подготовительного комплекса. В комплекс ритуально пищи входит жертвенное мясо, мясной бульон, молочные и злаковые продукты.

На моление Дьажыл бюр забивается жертвенный баран, реже лошадь. Жертвенное животное обычно выделяют частные фермерские, личные подсобные хозяйства, иногда то или иное поселение данного района, также не редко животное предоставляет отдельно взятый человек от своего имени.

Забивают животное за день до моления, считается, что жертвенное мясо должно остыть. При этом в день проведения обряда мясо привозят заранее и приступают к варке ранним утром, чтобы к восьми утра мясо было уже готово. Варят непременно в больших котлах, нужно чтобы было достаточное количество бульона мюн, который также является подношением духам, особенностью ритуального мюн, является отсутствие соли, считается, что соль может обжечь рот духа и такое подношение не будет принято.
Помимо мяса, также готовят молочные и злаковые подношения. Обязательным подношением, которым проводят окропление, огня, сторон света, жертвенников является молоко. Для ритуальных целей используется только свежее, еще никем не испробованное молоко. При этом важным является то, что в ритуалах Дьажыл бюр духам преподносится молоко нового весенне-летнего сезона, по сути речь идет о семильной магии, когда подобное порождает подобное, так свежее, с хорошей жирностью молоко нового цикла на обряде должно способствовать хорошим удоям на протяжении всего весенне-летнего сезона.

В качестве подношений также используются традиционные продукты, являющиеся производными из молока, как: кисломолочный сырчик - курут, пресный сыр - быштак, топленое масло - сардьу, засушенные кислосладкие творожные массы - аарчы, эдьигей.

Из злаковых подношений, которые также готовятся без использования соли и сахара, это лепешки - mеертпек, жареные пончики - боорсок, которые, в свою очередь, бывают разных форм, от круглых шариков, до сплетений, повторяющих плетение аркана и растительных узоров. Ритуальные лепешки и жареные пончики готовятся без соли и без использования ножа. Так отверстие в середине лепешки, необходимое для того, чтобы она равномерно прожарилась, проделывают пальцами. В противном случае такая лепешка не будет «живой». Также в качестве подношения используются жареные и измельченные в зернотерке зерна ячменя - талкан. Злаковые блюда также должны быть свежими, не засохшими, поэтому обычно их готовят за день до обряда [1, c. 195-196].

Категорически запрещено в ритуальный набор брать алкогольную продукцию, исключение делается для традиционного алтайского молочного самогона сют аракы, крепость которого в среднем 3-4, самогоном алкышчы производит кропление духам.

Относительно процесса совершения ритуального подношения пищи мы только обозначим, что процедура подношения условно делиться на две части, первая, когда подношения делает ведущий обряда, главное ответственное лицо начинающий весь комплекс ритуалов, и вторая, когда свои подношения делают все остальные участники моления.

Ритуальная пища во время совершения обряда кладется в горящий костер на специальных каменных жертвенниках тагыл, которые представляют собой прямоугольные или круглые каменные сооружения в высоту от 50 см до 1 метра. Весь обряд занимает около 3-4 часов и заканчивается коллективной трапезой участников. 
Обобщая контуры темы ритуальной пищи в современной алтайской культуре, нужно отметить что, не смотря на рост культуры массового потребления, относительной доступности продуктов пищевой промышленности, в обрядовой жизни коренные жители Горного Алтая придерживаются строгих канонов традиционной пищи, как и способов его приготовления. Так пищевой набор для подношений включает мясные, молочные и злаковые продукты. Хорошая сохранность ритуальной пищи отчасти объясняется потребностью людей заручиться поддержкой сверхъестественных сил в сохранности и росте плодородия домашних животных, полей, здоровья человека. Также с конца XX в., ростом процессов возрождения культуры и традиций, традиционная пища вообще, как и ее ритуальная часть, стали выражением этнической идентичности носителей культуры.

\section{ЛИТЕРАТУРА}

1. Обрядность в традиционной культуре алтайцев. Коллективная монография / БНУ РА «НИИ алтаистики им. С.С. Суразакова»; Редколлегия: Екеев Н.В. (отВ. ред.), Кузьмина Е.Н. (науч. ред.), Конунов А.А., Тадышева Н. О. - Горно-Алтайск: БНУ РА «НИИ алтаистики им. С.С. Суразакова», 2019. - 704 с.

2. Ц Цыбульский В.В. Календари и хронология стран мира. - М.: Изд-во «Просвещение», 1982. - 128 с.

3. Ямаева Е.Е. Астральная мифология и традиционный календарь алтайцев. - Горно-Алтайск, 2004. - 56 с.

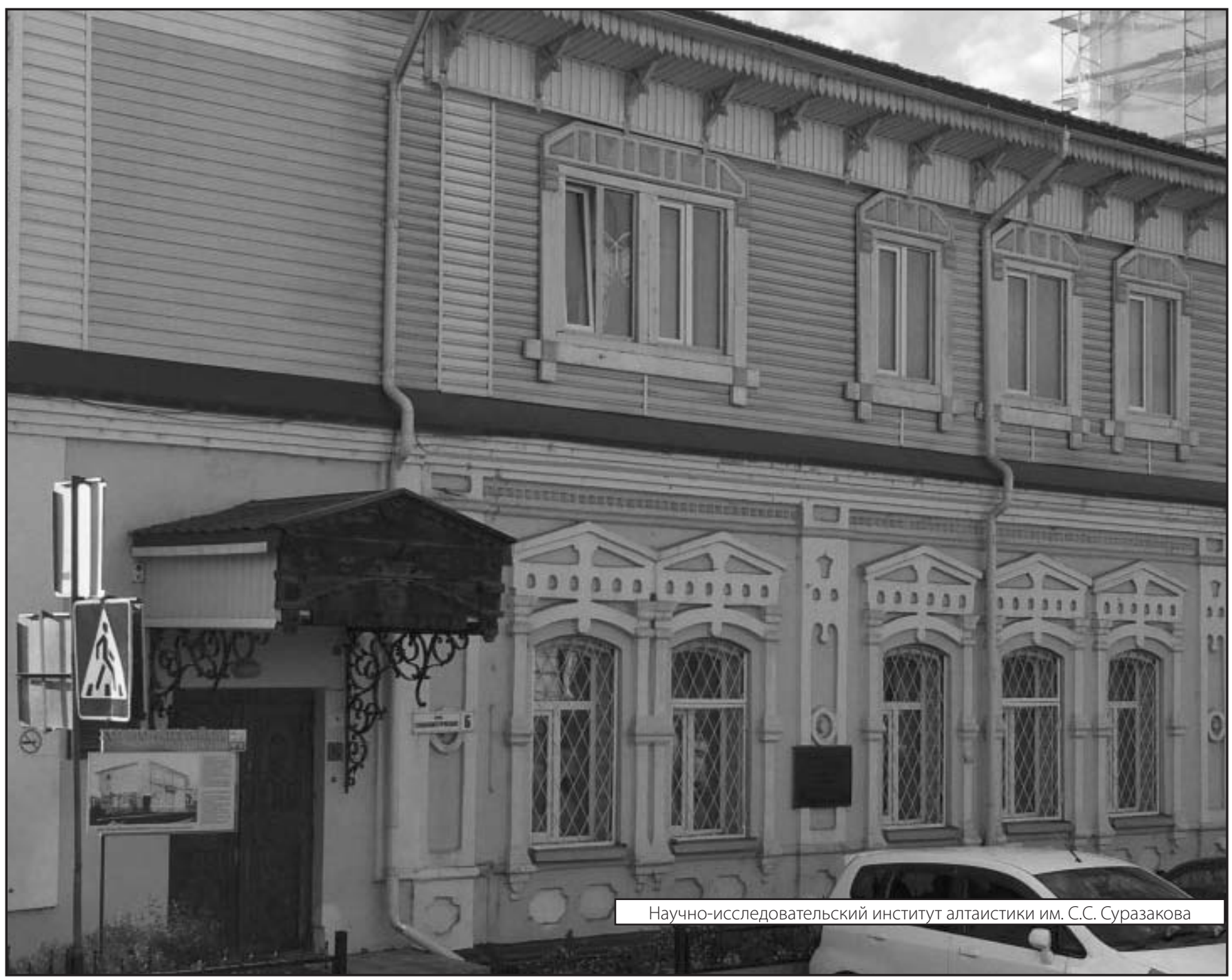

